\title{
Effect of oxytetracycline administration on intestinal metabolism of oestrogens and on plasma sex hormones in healthy men
}

\author{
E HÄMÄLÄINEN, J T KORPELA, AND H ADLERCREUTZ \\ From the Dept. of Clinical Chemistry, University of Helsinki, Meilahti Hospital, Finland
}

SUMmARY The effect of oxytetracycline (1 g/day for five days) on the enterohepatic recycling of oestrogens and on plasma sex hormone concentrations was assessed in healthy men. Plasma oestrone (E1), oestradiol-17 $\beta$ (E2), 4-androstenedione (A), $5 \alpha$-dihydrotestosterone (5 $\alpha$-DHT), total and free testosterone ( $\mathrm{T}$ and free $\mathrm{T}$ ), binding capacity of sex hormone binding globulin, luteinizing hormone, dehydroepiandrosterone-sulphate, urinary total E1, E2, and oestriol (E3), and oestriol-3-glucuronide (E3-3G) and faecal unconjugated and conjugated E1, E2, and E3 were measured by radioimmunoassay (RIA). Treatment with the antibiotic significantly increased the excretion of faecal conjugated oestrogens, which parallelled a decrease in urinary oestrogen excretion, especially of E3. The effect on urinary E3 could be explained almost entirely by the simultaneous decrease of urinary E3-3G concentrations. In urine and faeces the E2/E3 and $\mathrm{E} 1+\mathrm{E} 2 / \mathrm{E} 3$ ratios increased, probably because of the diminished reductive metabolism of oestrogens in the gut. No significant effects on plasma unconjugated oestrogen concentrations were observed. Moreover, in the present study oxytetracycline had no remarkable effect on plasma total, or free $\mathrm{T}$ concentrations, nor on other plasma hormones measured. Our results suggest that enterohepatic recycling and intestinal metabolism of oestrogens may be significant in men. The mechanism of action of antibiotics on oestrogen metabolism probably involves decreased hydrolysis by $\beta$-glucuronidase of oestrogen conjugates by the intestinal contents, diminishing the reabsorption of aglycones of oestrogen conjugates and resulting in faecal loss of the steroids.

In man the presence of an enterohepatic circulation (EHC) of steroid hormones is well established. After the metabolism and conjugation a substantial part of blood oestrogens,' but only a minor part of androgens, ${ }^{2}$ is excreted into bile. After hydrolysis in the intestinal tract, the aglycones are reabsorbed into the circulation partly as unconjugated steroids. ${ }^{3-5}$ The physiological role of this recycling is evidently twofold. Firstly, the half life of steroid hormones in the body is prolonged. ${ }^{13}$ Secondly, as a result of intestinal bacterial metabolism, biliary steroid hormones may be converted to biologically more active metabolites, ${ }^{56}$ which upon reabsorption may significantly

Address for correspondence: E. Hämäläinen MD, Dept of Clinical Chemistry, University of Helsinki, Meilahti Hospital. SF-(0)29) Helsinki 29. Finland.

Received for publication 23 July 1986. contribute to the concentrations of sex hormones in circulation.

The clinical importance of enterohepatic recycling in overall oestrogen metabolism in women is shown by the effects of oral antibiotic treatment and diet composition on plasma, urinary, and faecal oestrogens. Lower concentrations of plasma and urinary oestrogens and increased excretion of oestrogens in faeces have been observed in pre- and postmenopausal women after administration of various antibiotics and in female subjects consuming a low fat, high fibre diet. ${ }^{7-13}$ This effect has, at least partly, been attributed to a change of intestinal microflora and its hydrolytic capacity ( $\beta$-glucuronidase), which interrupts the enterohepatic recycling of oestrogens and leads to a loss of poorly absorbed biliary oestrogen conjugates in faeces. ${ }^{+512-14}$ Antibiotics probably have 
similar, but less intense, effects on progesterone and androgen recycling. ${ }^{1+15}$

Despite the extensive studies on enterohepatic recycling of oestrogens and neutral steroids in women, the role of intestinal factors in the regulation of the overall steroid hormone metabolism in men is almost completely unknown. ${ }^{56}$ Furthermore, it has previously been shown that serum testosterone concentrations in men are reduced during tetracycline administration and after a change to a low fat, high fibre diet, ${ }^{17}{ }^{18}$ and the mechanism involved is not resolved. We therefore have addressed the problem by investigating the effect of an antimicrobial agent on the enterohepatic recycling of oestrogens and on the plasma levels of sex hormones in male volunteers before, during and after oral administration of oxytetracycline.

\section{Methods}

\section{SUBJECTS}

Five young, healthy men, aged $24-30$ years, volunteered for the study and were monitored as outpatients. Because treatment with wide spectrum antibiotic may cause side effects in human subjects, men were recruited from the medical staff of our laboratory and they were well aware of the possible risks of medication. All were healthy, there was no evidence of endocrinological or other diseases and all the subjects had abstained from the use of antibiotics and other drugs for at least six months before the investigation. During the entire study the subjects consumed their normal Finnish diet of a mixed Western type.

\section{GENERAL PROCEDURES}

The men were given $1 \mathrm{~g}$ oxytetracycline (Terramycin, Pfizer, USA) in two doses orally per day for five days. Blood samples for hormone analyses were collected from each participant in heparinised tubes in the mornings (between 730 and $900 \mathrm{am}$ ) three days before, during, and four days after the antibiotic treatment and also on days 16, 17, and 18 after the start of the study. After centrifugation the plasma samples (usually three separate samples from each subject at 20 minute intervals) were stored at $-20^{\circ} \mathrm{C}$ until analysed.

Twenty four hour urine samples for urinary E1, E2, E3, and E3-3G determinations were obtained during the same day as the plasma samples. Faecal conjugated and unconjugated E1, E2, and E3 were measured in a 72 hour faecal pools before, in three 48 hour pools during and in two 72 hour pools after the antibiotic treatment. The urinary and faecal samples were collected and after the addition of ascorbic acid, they were pooled, homogenised and stored at $-20^{\circ} \mathrm{C}$ as previously described. ${ }^{12}$

During the study no side effect such as diarrhoea, occurred in any of the participants.

\section{HORMONE ANALYSES}

Plasma 4-androstenedione (A), 5 $\alpha$-dihydrotestosterone $(5 \alpha-\mathrm{DHT})$, testosterone (T) and unconjugated oestrone (E1) and oestradiol-17 $\beta$ (E2) were assayed as described by Hämäläinen. ${ }^{19}$ The percentage of plasma free testosterone (free $T$ ) was determined by a precipitation method of Bergink et al $l^{20}$ and plasma free $T$ was calculated on the basis of these and total $T$ results. The binding capacity of sex hormone binding globulin was measured by a slight modification of the method of Rosner. ${ }^{21} 22$

Plasma luteinizing hormone and dehydroepiandrosterone-sulphate were measured by commercial RIA kits from CIS international (France). The methodology for urinary E1, E2, E3, and E3-3G and faecal conjugated and unconjugated $\mathrm{E} 1, \mathrm{E} 2$, and E3 has been described in detail previously..$^{2324}$

\section{STATISTICAL ANALYSIS}

The means and standard error of means (SE) are presented. Because of the wide and skewed distributions, oestrogen results are shown as geometric means and standard error ranges, which are the antilogarithmics of geometric means \pm SE. The changes were tested against the mean values of three control days or against the values of first collection period utilising a non-parametric sign test for matched samples. ${ }^{25}$ Probability $(p)$ less than 0.05 was considered statistically significant.

\section{Results}

The excretion of faecal conjugated and unconjugated oestrogens in five healthy men before, during and after oxytetracycline administration is summarised in Table 1. During the three days control period oestrogen excretion showed a wide variation between individuals. The total amounts of oestrogens excreted (geom. mean and SE-ranges) were 1.54 $\mathrm{nmol} / 24 \mathrm{~h}(0 \cdot 56-3 \cdot 80)$ for $\mathrm{E} 1,1 \cdot 29 \mathrm{nmol} / 24 \mathrm{~h}(0 \cdot 57-$ 2.93) for E2 and $2 \cdot 34 \mathrm{nmol} / 24 \mathrm{~h}(0 \cdot 88-6 \cdot 78)$ for E3. Less than $10 \%$ of $E 1$ and $E 2$ and about $12 \%$ of $E 3$ were in conjugated form.

Oxytetracycline caused a significant and transient increase in the faecal concentrations of conjugated oestrogens in all subjects (Table 1) and thus, a huge increase in their excretion via faecal route. The peak values for different oestrogens occurred between the third and fifth collection periods resulting in the highest mean increase during the 8th and 9th day. The magnitude of the increase was variable and the 
Table 1 Effect of oxytetracycline administration $(2 \times 500 \mathrm{mg} /$ day $)$ on the daily excretion of faecal conjugated and unconjugated oestrogens in five healthy young men (pmol of oestrogen per gram of faecal dry weight). The results are expressed as geometric means and SE ranges. Oxytetracycline was given on days 4 to 9

\begin{tabular}{|c|c|c|c|c|c|c|c|}
\hline \multirow[b]{2}{*}{ Days } & \multicolumn{3}{|c|}{$\begin{array}{l}\text { Conjugated faecal oestrogens } \\
\text { (pmol/g/24h) }\end{array}$} & \multicolumn{3}{|c|}{$\begin{array}{l}\text { Unconjugated faecal oestrogens } \\
\text { (pmol/g/24h) }\end{array}$} & \multirow{2}{*}{$\begin{array}{l}\text { Faecal dry } \\
\text { weight } \\
(\text { g/24h) } \\
\text { mean } \\
\pm S E M\end{array}$} \\
\hline & $\begin{array}{l}\text { Oestrone } \\
\text { meant } \\
S E \text {-range }\end{array}$ & $\begin{array}{l}\text { Oestradiol } \\
\text { mean } \pm \\
S E \text {-range }\end{array}$ & $\begin{array}{l}\text { Oestriol } \\
\text { mean } \pm \\
S E \text {-range }\end{array}$ & $\begin{array}{l}\text { Oestrone } \\
\text { meant } \\
S E \text {-range }\end{array}$ & $\begin{array}{l}\text { Oestradiol } \\
\text { mean } \pm \\
\text { SE-range }\end{array}$ & $\begin{array}{l}\text { Oestriol } \\
\text { mean士 } \\
S E \text {-range }\end{array}$ & \\
\hline $1-3$ & $\begin{array}{l}1 \cdot 4 \\
(1 \cdot 1-1 \cdot 8)\end{array}$ & $\begin{array}{l}0 \cdot 6 \\
(0.5-0 \cdot 8)\end{array}$ & $\begin{array}{l}3 \cdot 1 \\
(2 \cdot 2-4 \cdot 3)\end{array}$ & $\begin{array}{l}23 \cdot 9 \\
(19 \cdot 1-30 \cdot 0)\end{array}$ & $\begin{array}{l}20 \cdot 6 \\
(16 \cdot 9-26 \cdot 5)\end{array}$ & $\begin{array}{l}33 \cdot 7 \\
(25 \cdot 3-44 \cdot 9)\end{array}$ & $\begin{array}{l}62.5 \\
\pm 11.5\end{array}$ \\
\hline $4-5$ & $\begin{array}{l}2 \cdot 0 \\
(1 \cdot 7-2 \cdot 4)\end{array}$ & $\begin{array}{l}1 \cdot 4^{*} \\
(1 \cdot 1-1 \cdot 8)\end{array}$ & $\begin{array}{l}6 \cdot 8^{*} \\
(5 \cdot 4-8 \cdot 6)\end{array}$ & $\begin{array}{l}44 \cdot 4 \\
(30 \cdot 2-65 \cdot 4)\end{array}$ & $\begin{array}{l}18 \cdot 3 \\
(14 \cdot 7-22 \cdot 9)\end{array}$ & $\begin{array}{l}23 \cdot 3 \\
(18 \cdot 4-29 \cdot 5)\end{array}$ & $\begin{array}{l}38 \cdot 0 \\
\pm 4 \cdot 9\end{array}$ \\
\hline$\underline{6-7}$ & $\begin{array}{l}9 \cdot 2^{*} \\
(4 \cdot 4-19 \cdot 6)\end{array}$ & $\begin{array}{l}3 \cdot 7^{*} \\
(2 \cdot 3-5 \cdot 9)\end{array}$ & $\begin{array}{l}20 \cdot 9 * \\
(11 \cdot 2-39 \cdot 1)\end{array}$ & $\begin{array}{l}26 \cdot 9 \\
(23 \cdot 0-31 \cdot 5)\end{array}$ & $\begin{array}{l}16 \cdot 6 \\
(12 \cdot 9-20 \cdot 3)\end{array}$ & $\begin{array}{l}27 \cdot 1 \\
(19 \cdot 5-37 \cdot 7)\end{array}$ & $\begin{array}{l}53 \cdot 0 \\
\pm 11 \cdot 1\end{array}$ \\
\hline$\underline{8-9}$ & $\begin{array}{l}10 \cdot 1^{*} \\
(5 \cdot 1-20 \cdot 1)\end{array}$ & $\begin{array}{l}4 \cdot 6^{*} \\
(3 \cdot 4-6 \cdot 3)\end{array}$ & $\begin{array}{l}21 \cdot 4^{*} \\
(12 \cdot 4-37 \cdot 0)\end{array}$ & $\begin{array}{l}30 \cdot 2 \\
(24 \cdot 7-36 \cdot 9)\end{array}$ & $\begin{array}{l}28 \cdot 6 \\
(23 \cdot 8-34 \cdot 3)\end{array}$ & $\begin{array}{l}20 \cdot 6 \\
(11 \cdot 6-36 \cdot 5)\end{array}$ & $\begin{array}{l}54 \cdot 6 \\
\pm 7 \cdot 4\end{array}$ \\
\hline $10-12$ & $\begin{array}{l}6 \cdot 5^{*} \\
(3 \cdot 7-11 \cdot 5)\end{array}$ & $\begin{array}{l}3 \cdot 3^{*} \\
(2 \cdot 1-5 \cdot 2\end{array}$ & $\begin{array}{l}10 \cdot 6^{*} \\
(6 \cdot 3-17 \cdot 7\end{array}$ & $\begin{array}{l}30 \cdot 0 \\
(26 \cdot 2-34 \cdot 3)\end{array}$ & $\begin{array}{l}21 \cdot 9 \\
(20 \cdot 2-23 \cdot 7\end{array}$ & $\begin{array}{l}28 \cdot 7 \\
(25 \cdot 2-32 \cdot 7\end{array}$ & $\begin{array}{l}56 \cdot 7 \\
\pm 8 \cdot 1\end{array}$ \\
\hline $16-18$ & $\begin{array}{l}3 \cdot 0 \\
(1 \cdot 9-4 \cdot 8)\end{array}$ & $\begin{array}{l}1 \cdot 7^{*} \\
(1 \cdot 2-2 \cdot 5)\end{array}$ & $\begin{array}{l}6 \cdot 6^{*} \\
(4 \cdot 5-5 \cdot 1)\end{array}$ & $\begin{array}{l}28 \cdot 0 \\
(26 \cdot 7-29 \cdot 4)\end{array}$ & $\begin{array}{l}21 \cdot 4 \\
(20 \cdot 0-22 \cdot 8)\end{array}$ & $\begin{array}{l}25 \cdot 7 \\
(18 \cdot 9-35 \cdot 1)\end{array}$ & $\begin{array}{l}49 \cdot 0 \\
\pm 6 \cdot 8\end{array}$ \\
\hline $22-24$ & $\begin{array}{l}3 \cdot 7 \\
(3 \cdot 3-4 \cdot 2)\end{array}$ & $\begin{array}{l}2 \cdot 1^{*} \\
(1 \cdot 6-2 \cdot 7)\end{array}$ & $\begin{array}{l}9 \cdot 3^{*} \\
(7 \cdot 8-11 \cdot 0)\end{array}$ & $\begin{array}{l}22 \cdot 3 \\
(19 \cdot 6-25 \cdot 3)\end{array}$ & $\begin{array}{l}16 \cdot 0 \\
(14 \cdot 1-18 \cdot 0)\end{array}$ & $\begin{array}{l}32 \cdot 1 \\
(23 \cdot 4-44 \cdot 1)\end{array}$ & $\begin{array}{l}42 \cdot 3 \\
\pm 7 \cdot 0\end{array}$ \\
\hline
\end{tabular}

Days of oxytetracycline administration are underlined; ${ }^{*} \mathrm{p}<0 \cdot 05$

maximal rise was $16 \cdot 5$-fold for E1 followed by $12 \cdot 6$ fold for E2 and 10.4-fold for E3 (mean values). One subject showed a $25-40$-fold increase in faecal oestrogen conjugates, indicating that during antibiotic treatment he excreted from $66-97 \%$ of faecal oestrogens in this form, whereas in two subjects excretion increase varied from $2 \cdot 5-3$-fold. Oxytetracycline had no consistent effect on faecal unconjugated oestrogens (Table 1). In three subjects, however, the significant increases in faecal conjugated oestrogen concentrations were paralleled by marked rises in the excretions of unconjugated oestrogens.

Because of the great increase in the oestrogen conjugates, the total concentrations (conjugated+ unconjugated) of E1, E2, and E3 in faeces increased clearly in all subjects. During the 8 th and 9 th days the concentration rises compared with the mean of control period were from $24 \cdot 5$ to $53 \cdot 6$, from $21 \cdot 3$ to 34.2 and from 38.6 to $66.6 \mathrm{pmol} / \mathrm{g}$ faecal dry weight for E1, E2, and E3, respectively $(\mathrm{p}<0.05)$. The total daily output of faecal oestrogens was significantly influenced by the variation of faecal mass and thus, the increase in the daily excretion of E1, E2, and E3 was clearly observed only in three subjects. The ratios of faecal total E1 to E2, E2 to E3, and E1+E2 to E3 increased in all cases.

The response of urinary oestrogens to the antibiotic course is shown in Figure 1. Concomitantly with the faecal changes the excretion of oestrogens in urine decreased in all men. The most marked effect was observed for $\mathrm{E} 3$, which was significantly reduced to minimal values of $23-77 \%$ of the mean of control

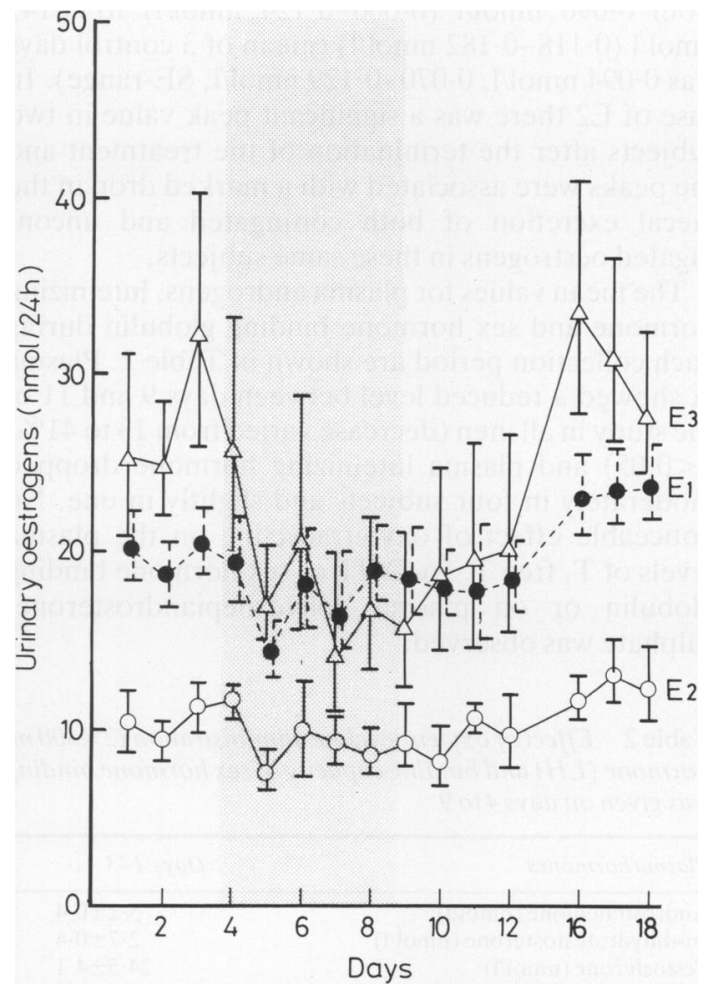

Fig. 1 Effect of oxytetracycline administration $(2 \times 500$ $\mathrm{mg}$ /day for five days, shaded area) on daily urinary oestrone (E1), oestradiol (E2), and oestriol (E3) excretion in five healthy young men. The results are shown as geometric means and $S E$ ranges. 
values in each participant (days $7-10$, all $p$ values $<0.05$ ). Urinary immunoreactive E3-3G showed a similar change as total E3 on days 5-9 ( $p<0.05$, decrease of $40-64 \%$, Fig. 2). Because of the lack of absolute specificity of our antiserum against E3-3G in our direct RIA, the levels of E3-3G in urine were somewhat higher than those of total E3 (Figs 1 and 2 ). Although the crossreacting compounds are not completely identified (probably 2-hydroxyoestrogens) we have obtained good linearity and reproducibility in our standard experiments for E3-3G, suggesting that this method is valid for monitoring this urinary glucuronide conjugate as a marker of EHC of oestrogens. The ratios of urinary $E 2 / E 3$ and $E 1+E 2 / E 3$ showed a clear tendency to increase in all subjects.

No consistent effect of the antibiotic was observed on the plasma concentrations of unconjugated oestrogens. The mean (and SE-range) plasma concentrations of five subjects for E1 varied from $0 \cdot 129$ $\mathrm{nmol} / \mathrm{l}(0 \cdot 097-0.173 \mathrm{nmol} / \mathrm{l})$ to $0 \cdot 161 \mathrm{nmol} / \mathrm{l}(0 \cdot 136-$ $0 \cdot 190 \mathrm{nmol} / \mathrm{l}$ ) (the mean of three control days was $0 \cdot 145 \mathrm{nmol} / \mathrm{l}, 0 \cdot 116-0 \cdot 176 \mathrm{nmol} / \mathrm{l}, \mathrm{SE}-\mathrm{range})$ and E2 from $0.090 \mathrm{nmol} / 1(0.066-0.124 \mathrm{nmol} / \mathrm{l})$ to $0 \cdot 147$ $\mathrm{nmol} / \mathrm{l}(0 \cdot 118-0 \cdot 182 \mathrm{nmol} / \mathrm{l})$ (mean of 3 control days was $0.094 \mathrm{nmol} / 1,0 \cdot 070-0 \cdot 129 \mathrm{nmol} / \mathrm{l}, \mathrm{SE}-\mathrm{range})$. In case of E2 there was a significant peak value in two subjects after the termination of the treatment and the peaks were associated with a marked drop in the faecal excretion of both conjugated and unconjugated oestrogens in these same subjects.

The mean values for plasma androgens, luteinizing hormone and sex hormone binding globulin during each collection period are shown in Table 2 . Plasma A showęd a reduced level between days 9 and 11 of the study in all men (decrease varied from 13 to $41 \%$, $\mathrm{p}<0.05$ ) and plasma luteinizing hormone dropped moderately in four subjects and slightly in one. No noticeable effect of oxytetracycline on the plasma levels of T, free T, $5 \alpha$-DHT or sex hormone binding globulin or on plasma dehydroepiandrosteronesulphate was observed.

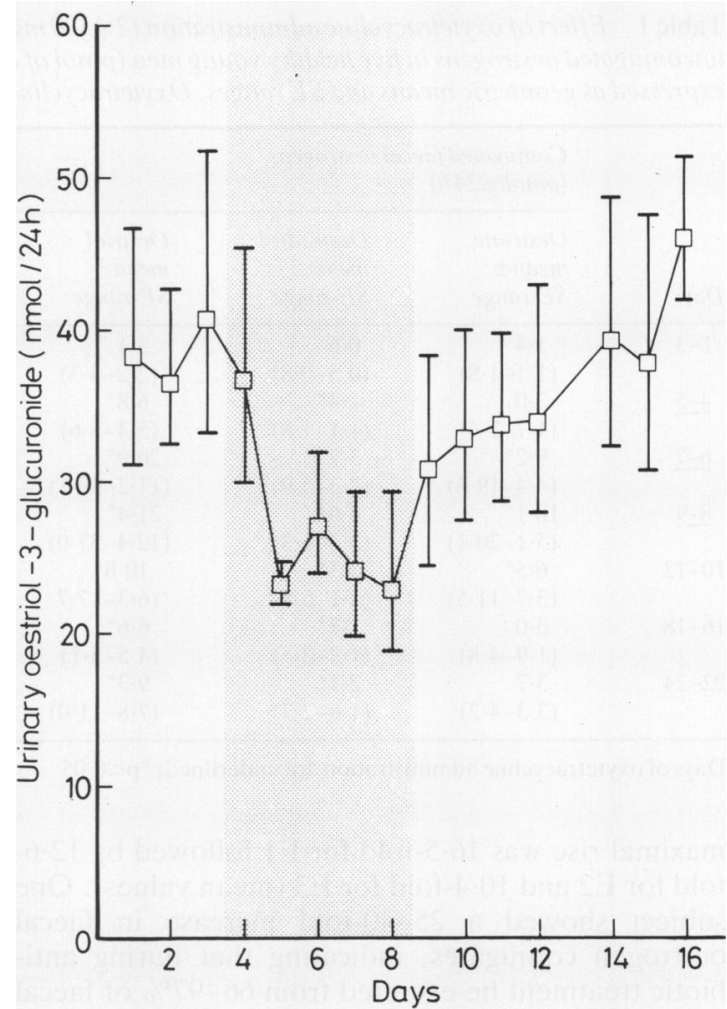

Fig. 2 Effect of oxytetracycline administration $(2 \times 500$ mg/day for five days, shaded area) on daily urinary oestriol3-glucuronide (E3-3G) excretion in five healthy young men. The results are shown as geometric means and $S E$ ranges.

\section{Discussion}

More than $99 \%$ of biliary oestrogens are conjugated. Having entered the gut about $80 \%$ are reabsorbed mainly as free steroids after extensive hydrolysis by enzymes of mainly bacterial origin. ${ }^{2-5}$ Thus, based on the studies with female subjects, it has been said that the main effect of an oral antibiotic treatment on

Table 2 Effect of oxytetracycline administration $(2 \times 500 \mathrm{mg} /$ day) on plasma concentrations of androgens, luteinizing hormone $(\mathrm{LH})$ and binding capacity of sex hormone binding globulin (SHBG) in five healthy young men. Oxytetracycline was given on days 4 to 9

\begin{tabular}{|c|c|c|c|c|c|c|}
\hline Plasmahormones & Days 1-3 & $\underline{4-5}$ & $\underline{6-7}$ & $\underline{8-9}$ & $10-12$ & $16-18$ \\
\hline Androstenedione (nmol/l) & $5 \cdot 1 \pm 0 \cdot 4$ & $4 \cdot 8 \pm 0 \cdot 5$ & $4 \cdot 8 \pm 0 \cdot 4$ & $4 \cdot 0 \pm 0 \cdot 4^{*}$ & $4 \cdot 6 \pm 0 \cdot 9^{*}$ & $4 \cdot 6 \pm 0 \cdot 6$ \\
\hline $5 \alpha$-dihydrotestosterone (nmol/l) & $2.7 \pm 0.4$ & $2 \cdot 9 \pm 0.6$ & $2 \cdot 4 \pm 0.5$ & $2 \cdot 3 \pm 0 \cdot 4$ & $2 \cdot 8 \pm 0.4$ & $2 \cdot 9 \pm 0 \cdot 3$ \\
\hline Testosterone $(\mathrm{nmol} / \mathrm{l})$ & $24 \cdot 5 \pm 4 \cdot 1$ & $25 \cdot 0 \pm 5 \cdot 2$ & $23 \cdot 3 \pm 4 \cdot 8$ & $23 \cdot 8 \pm 3 \cdot 1$ & $24 \cdot 9 \pm 6 \cdot 6$ & $23 \cdot 3 \pm 3 \cdot 9$ \\
\hline Free testosterone $(\mathrm{pmol} / \mathrm{l})$ & $327 \pm 69$ & $302 \pm 74$ & $312 \pm 79$ & $292 \pm 61$ & $316 \pm 84$ & $297 \pm 64$ \\
\hline Dehydroepiandrosterone (-sulphate) (umol/l) & $9 \cdot 7 \pm 1 \cdot 4$ & $9 \cdot 2 \pm 0 \cdot 9$ & $8 \cdot 9 \pm 1 \cdot 1$ & $8 \cdot 7 \pm 1 \cdot 2$ & $8 \cdot 9 \pm 1 \cdot 1$ & $8.9 \pm 0.9$ \\
\hline Luteinizing hormone (IU//) & $6 \cdot 5 \pm 0 \cdot 6$ & $6 \cdot 3 \pm 0 \cdot 8$ & $5 \cdot 7 \pm 0 \cdot 4$ & $5.8 \pm 0.6$ & $6 \cdot 5 \pm 0 \cdot 8$ & $6 \cdot 8 \pm 1 \cdot 0$ \\
\hline SHBG $(\mathrm{nmol} / \mathrm{l})$ & $27 \cdot 0 \pm 4 \cdot 4$ & $25 \cdot 0 \pm 5 \cdot 7$ & $25 \cdot 4 \pm 4 \cdot 3$ & $26 \cdot 0 \pm 3 \cdot 0$ & $26 \cdot 5 \pm 4 \cdot 2$ & $28 \cdot 2 \pm 2 \cdot 8$ \\
\hline
\end{tabular}

Days of oxytetracycline administration are underlined; *p $<0.05$ 
intestinal oestrogen metabolism is the inhibition of the deconjugation of oestrogen conjugates in gut. This may result in increased losses of oestrogen metabolites in faeces and reduced urinary excretion. ${ }^{+11}$ Accordingly, the present study shows that administration of oxytetracycline caused a significant increase in the concentrations of faecal oestrogens also in male subjects, caused mainly by a huge and variable rise in the levels of conjugated oestrogens (Table 1). These results were in agreement with previous observations in women. ${ }^{+5}$

Although the measurement of the unconjugated oestrogens revealed no consistent pattern, their excretion increased in parallel with faecal conjugated oestrogens in three subjects. This shows that the destruction of $\beta$-glucuronidase producing microflora by antibiotics is seldom complete. Thus, a significant deconjugation of the non-absorbed conjugated oestrogens occurs, probably in the lower part of large bowel, where the absorption of free steroids is no longer possible resulting in an increase also in unconjugated oestrogens. This view is further supported by our previous experiment in an erythromycin treated single male subject, in whom both the faecal unconjugated and conjugated oestrogens increased in a similiar manner. ${ }^{526}$

In vitro studies with antibiotics have proved that a reductive metabolism is dominant in the intestines. There exists an interconversion of E1 to E2 in faecal extracts by isolated bacterial strains sensitive to oxytetracycline such as Bacteroides fragilis ${ }^{+2728}$ Thus, in the present study increases in the ratios of total (conjugated+unconjugated) E2/E3 and E1+E2/E3 and particularly of E1/E2 in faeces during oxytetracycline administration indicates the production, by faecal microflora under normal conditions, of small quantities of the biologically more active E2 from biliary E1, a metabolic pathway not exclusive to women as we previously suggested."

The change of faecal oestrogen excretion resulted in the simultaneous reduction of urinary oestrogen concentrations, especially of E3, in all male subjects (Fig. 1). This is in conformity with the previous results in pregnant women and in an erythromycin treated single male. ${ }^{7 \times 26} \mathrm{E} 3-3 \mathrm{G}$ is a conjugate formed practically ęxclusively by the intestinal mucosa from gut absorbed E3 and having entered the circulation it is excreted directly in urine without further metabolism. ${ }^{29} .310$ Therefore, it is a 'marker' of enterohepatic circulation of oestrogens and an increase of E3 in faeces and a decrease of E3-3G in urine in all male subjects from the second to fifth days of antibiotic administration (Fig. 2) strongly indicates the interruption of the oestrogen recycling. ${ }^{314}$ Moreover, Tikkanen et al have shown that also in pregnant women the antibiotic effect on urinary E3 can almost entirely be explained by the remarkable reduction in E3-3G but less by the reduction in oestriol-16glucuronide (E3-16G) ${ }^{\mathrm{x}}$

The simultaneous increase in the excretion of faecal oestrogens with the reduction in urinary $E 1$, E2, E3, and especially E3-3G levels in all subjects and the parallel increase of faecal and urinary E2/E3 and $E 1+E 2 / E 3$ ratios support the hypothesis that the faecal loss of oestrogens is the underlying mechanism. It was surprising that the daily increase in the total faecal output of oestrogens, especially of E3, in all men was significantly smaller than the decrease of oestrogen excretion in urine. This may be, at least partly, explained by intestinal destruction or metabolism of oestrogens to metabolites that are not measured by RIA. In addition, the comparison of quantitative excretion of daily faecal and urinary oestrogens was difficult, because the daily output in faeces in different subjects varied significantly with faecal mass.

Despite the intestinal and urinary changes oxytetracycline had no consistent effect on plasma biologically active, unconjugated oestrogens (see text). As we did not measure plasma oestrogen conjugates, a possible decrease in plasma oestrone sulphate, which may be biologically active oestrogen in blood after hydrolysis, could not be observed in our male subjects. ${ }^{31}$ Whether the peak values in plasma E2 in two participants after the termination of oxytetracycline administration had any direct relationship to diminished loss of E2 in faeces and a possible return of the reductive intestinal metabolism and increased synthesis of E2 from E1 in the intestinal tract after antibiotic effect remains to be established.

Antibiotics have been shown to influence plasma androgen concentrations in men. Rifampicin increases plasma total $\mathrm{T}$ concentrations in healthy men probably through the stimulation of testicular 17-hydroxylase. ${ }^{32}{ }^{33}$ Tetracycline has been reported to reduce plasma $\mathrm{T}$ concentrations and 'free $\mathrm{T}$ index' in male acne patients and the possible role of the antibiotics on the intestinal metabolism of steroids have been discussed. ${ }^{17}$ In this study, however, oxytetracycline had no remarkable effect on plasma concentrations of T, free T, $5 \alpha$-DHT, sulphate conjugated dehydroepiandrosterone-sulphate or sex hormone binding globulin levels were observed. Because, the pharmacological properties of tetracycline and oxytetracycline are almost identical, ${ }^{34}$ the controversial results between this work and previous studies may be due to our slightly lower antibiotic doses, the fact that our healthy subjects were without any previous medication or to our more specific androgen methodology. On the other hand, we cannot exclude the possibility that the decrease in plasma T (about $15 \%$ ), found by Pulkkinen et al was 
too slight to be demonstrated owing to our small study group and considerable within individual variation in plasma $\mathrm{T}$ concentrations. Indeed, the tendency of plasma $\mathrm{A}$ and luteinizing hormone to decrease after oxytetracycline administration suggest that a small subclinical change in pituitary-testicularaxis in our men may have taken place.

We conclude that the role of intestinal compartment in the overall oestrogen metabolism is significant in men. About $10 \%$ (two to $20 \%$ in different subjects) of E1, E2, and E3 of total oestrogen elimination in faeces and urine is via a faecal route. This excretion is significantly increased by antibiotic, oxytetracycline, and simultaneously a shift from urinary to faecal excretion takes place. The mechanism involved is probably a reduction in hydrolytic activity of $\beta$-glucuronidase in the intestinal content causing a diminished reabsorption of the aglycones of biliary oestroen conjugates and a loss of steroids in faeces.

Despite this effect on intestinal metabolism, we did not find any consistent change in plasma biologically active, unconjugated oestrogens. In addition, contrary to previous reports, our tetracycline derivative did not induce any signficant changes in plasma total and free $T$ concentrations, although a small tendency to decrease was observed in the plasma levels of $\mathrm{A}$ and luteinizing hormone in all male subjects.

We would like to thank Ms Inga Wiik, Ms Rauni Lehtola, Ms Aila Heikkinen and Ms Virpi Hämäläinen for skilful technical and secretarial assistance. This study was supported by The Yrjö Jahnsson Foundation, Helsinki, Finland and the Medical Research Council of the Academy of Finland.

\section{References}

1 Adlercreutz H. Studies on oestrogen excretion in human bile. Acta Endocrin suppl. 1962; 72: 1-220.

2 Peterson RE. Biliary excretion of neutral steroids in man. In: Taylor W, ed. The biliary system: a symposium of the Nato Advanced Study Institute. Oxford: Blackwell, 1965: 385-96.

3 Adlercreutz H, Luukkainen T. Biochemical and clinical aspects of the enterohepatic circulation of oestrogens. Acta Endodrinol suppl. 1967; 124: 101-140.

4 Adlercreutz H, Martin F, Pulkkinen M, et al. Intestinal metabolism estrogens. J Clin Endocrinol Metab 1976; 43: 497-505.

5 Adlercreutz H, Martin F, Järvenpää P, Fotsis T. Steroid absorption and enterohepatic recycling. Contraception 1979; 20: 201-23.

6 Goddard P, Hill MJ. Degradation of steroids by intestinal bacteria IV. The aromatization of ring A. Biochem Biophys Acta 1972; 280: 336-42.
7 Willman K, Pulkkinen MO. Reduced maternal plasma and urinary estriol during ampicillin treatment. $A m J$ Obstet Gynecol 1971; 109: 893-6.

8 Tikkanen MJ, Pulkkinen MO, Adlercreutz H. Effect of ampisillin treatment on the urinary excretion of estriol conjugates in pregnancy. J Steroid Biochem 1973; 4: 439-40.

9 Pulkkinen MO, Willman K. Maternal estrogen levels during penicillin treatment. Br Med J 1971; 4: 48.

10 Van Look PFA, Top-Huisman M, Gnodde HP. Effect of ampicillin or amoxycillin administration on plasma and urinary estrogen levels during normal pregnancy. Eur J Obstet Gynecol 1981; 12: 225-33.

11 Pulkkinen MO, Willman K. Reduction of maternal estrogen excretion by neomycin. Am J Obstet Gynecol 1973; 115: 1153.

12 Goldin BR, Adlercreutz H, Gorbach SL, Warram JH, Dwyer JT, Swenson L, Woods MN. Estrogen excretion patterns and plasma levels in vegetarian and omnivorous women. N Engl J Med 1982; 307: 1542-7.

13 Reference deleted.

14 Adlercreutz H, Martin F. Biliary excretion and intestinal metabolism of progesterone and estrogens in man. J Steroid Biochem 1980; 13: 231-44.

15 Martin F, Bhargava AS, Adlercreutz H. Androgen metabolism in beagle: Endogenous $\mathrm{C}_{19} \mathrm{O}_{2}$ metabolites in bile and effect of ampicillin administration. J Steroid Biochem 1977; 8: 753-60.

16 Adlercreutz H, Martin F, Lindström B. Gas chromatographic and mass spectrometric studies on oestrogens in bile - 2. Men and non-pregnant women. J Steroid Biochem 1978; 9: 1197-205.

17 Pulkkinen MO, Mäenpää J. Decrease in serum testosterone concentration during treatment with tetracycline. Acta Endocrinol 1983; 103: 269-72.

18 Hämäläinen E, Adlercreutz H, Puska P, Pietinen P. Diet and serum sex hormones in healthy men. J Steroid Biochem 1984; 20: 459-64.

19 Hämäläinen E. A micromethod for the simultaneous determination of clinically important androgens and oestrogens in plasma. Scand J Clin Lab Invest 1982; 41: 493-8.

20 Bergink EW, Holma P, Pyörälä T. Effects of oral contraceptive combinations containing levonorgestrol or desogestrel on serum proteins and androgen binding. Scand J Clin Lab Invest 1981; 41: 663-8.

21 Rosner W. A simplified method for the quantitative determination of testosterone-estradiol binding globulin activity in human plasma. J Clin Endocrinol Metab 1972; 34: $983-8$.

22 Kuoppasalmi K. Plasma testosterone and sex-hormonebinding globulin in physical exercise. Scand J Clin Lab Invest 1980; 40: 411-8.

23 Adlercreutz $\mathrm{H}$, Fotsis T, Heikkinen R. Current state of art in the analysis of estrogens. In: Görög $S$, ed. Advances in steroid analysis. Budapest: Akademiai Kiado. 1982: 3-33.

24 Adlercreutz H, Järvenpää P. Assay of estrogens in human feces. J Steroid Biochem 1982; 17: 639-45.

25 Wonnacott TH, Wonnacott RJ. Introductory statistics. New York-Chichester-Brishane-Toronto: Wiley and Sons. 1977: 473-4. 
26 Adlercreutz H, Pulkkinen $\mathrm{MO}$, Hämäläinen EK, Korpela JT. Studies on the role of intestinal bacteria in metabolism of synthetic and natural steroid hormones. $J$ Steroid Biochem 1984; 20: 217-29.

27 Lombardi P, Bouldin B, Boutin E, Gorbach SL. Metabolism of androgens and estrogens by human fecal micro-organisms. J Steroid Biochem 1978; 9: 795-801.

28 Järvenpää $\mathrm{P}$, Kosunen $\mathrm{T}$, Fotsis $\mathrm{T}$, Adlercreutz H. In vitro metabolism of estrogens by isolated intestinal micro-organisms and by human fecal microflora. $J$ Steroid Biochem 1980; 13: 345-9.

29 Goebelsmann U, Cooke I, Wiqvist N, Diczfalusy E. Comparison of the metabolism of oestriol-3glucosiduronate and oestriol-16-glucosiduronate in pregnant women. Acta Endocrinol 1966; 52: 30-42.

30 Stöa. KF, Levitz M. Comparison of conjugated meta- bolites of intraduodenally administered oestriol. Acta Endocrinol 1968; 57: 657-68.

31 Adlercreutz H, Martin F, Lehtinen T, Tikkanen MJ, Pulkkinen MO. Effect of ampicillin administration on plasma conjugated and unconjugated estrogen and progesterone levels in pregnancy. Am J Obstet Gynecol 1977; 128: 266-71.

32 Nocke-Finck L, Breuer H, Reimers D. Wirkung von Rifampicin und Streptomycin auf die Konzentrationen von Testosteron und Cortisol in Blut von Männern. $J$ Chem Biochem 1980; 18: 897-9.

33 Nocke-Finck L, Breuer $\mathrm{H}$. Effect of rifampicin on the biosynthesis of testosterone in rat testis. Acta Endocrinol 1981; 97: 573-6.

34 Weinstein L. III. Tetracyclines. In: Goodman LS, Gilman A, eds. The Pharmacological basis of therapeutics. New York: Macmillan. 1970: 1253-68. 